\title{
Serial Powerpoint Presentasi: Menentukan Derajat Karstifikasi (Karstification Degree) akuifer Karst
}

Dr. Tjahyo Nugroho Adji., MSc.Tech Asyroful Mujib, MSc Universitas Gadjah Mada 


\section{Contents}

\section{Latar Belakang}

2 Metode Rashed

3 Metode Malik and Votjkova

4 Referensi 


\section{Latar Belakang}

\section{Karakteristik Imbuhan Airtanah}

(Recharge)

Tingkat Perkembangan Akuifer Karst (Derajat Karstifikasi)

\section{Kapasitas Simpanan Akuifer} (Storage)

Sifat akuifer dalam melepaskan air (Flow)

Derajat Karstifikasi Rendah

\section{Derajat Karstifikasi Tinggi}




\section{Metode perhitungan Derajat Karstifikasi}

\section{Metode Perhitungan \\ Derajat Karstifikasi}

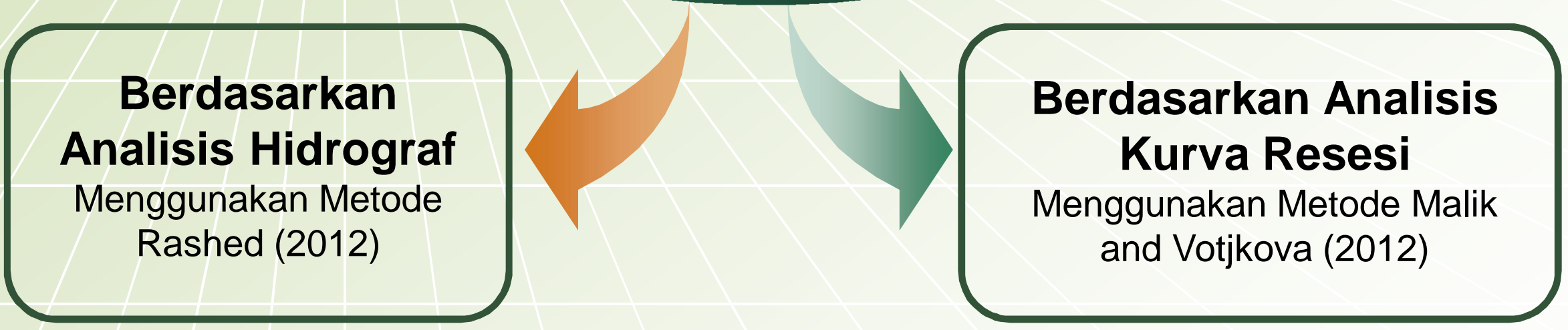




\section{Metode Perhitungan Derajat Karstiffkasi}

\section{METODE RASHED (2012)}

\section{Berdasarkan Analisis Hidrograf}
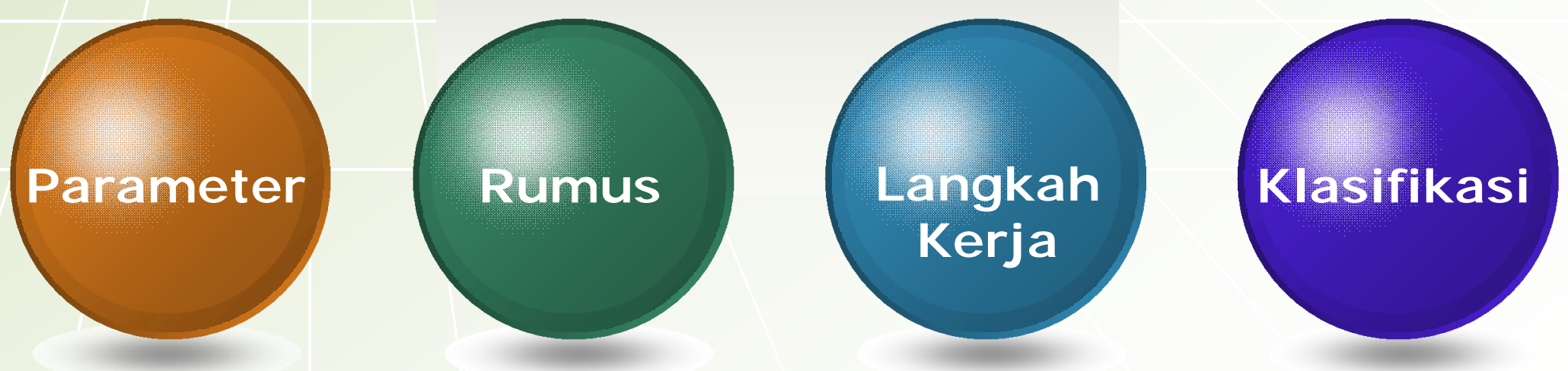


\section{Metode Perhitungan Rashed (2012)}

\section{Pendekatan}

\section{Dasar Perhitungan}

\section{Pendekatan Analisis Hidrograf Banjir}

Perhitungannya mulai dari naiknya debit hingga debit kembali lagi menjadi aliran dasar (baseflow)

\section{Parameter}

1. Debit Minimum saat kurva mulai naik (A)

2. Debit Maksimum (C)

3. Waktu mulai dari naiknya debit hingga debit puncak ( $t_{c}$ atau $t_{\text {peak }}$ )

4. Waktu mulai dari naiknya debit hingga debit kembali menjadi normal $\left(t_{b}\right.$ atau $\left.t_{\text {event }}\right)$

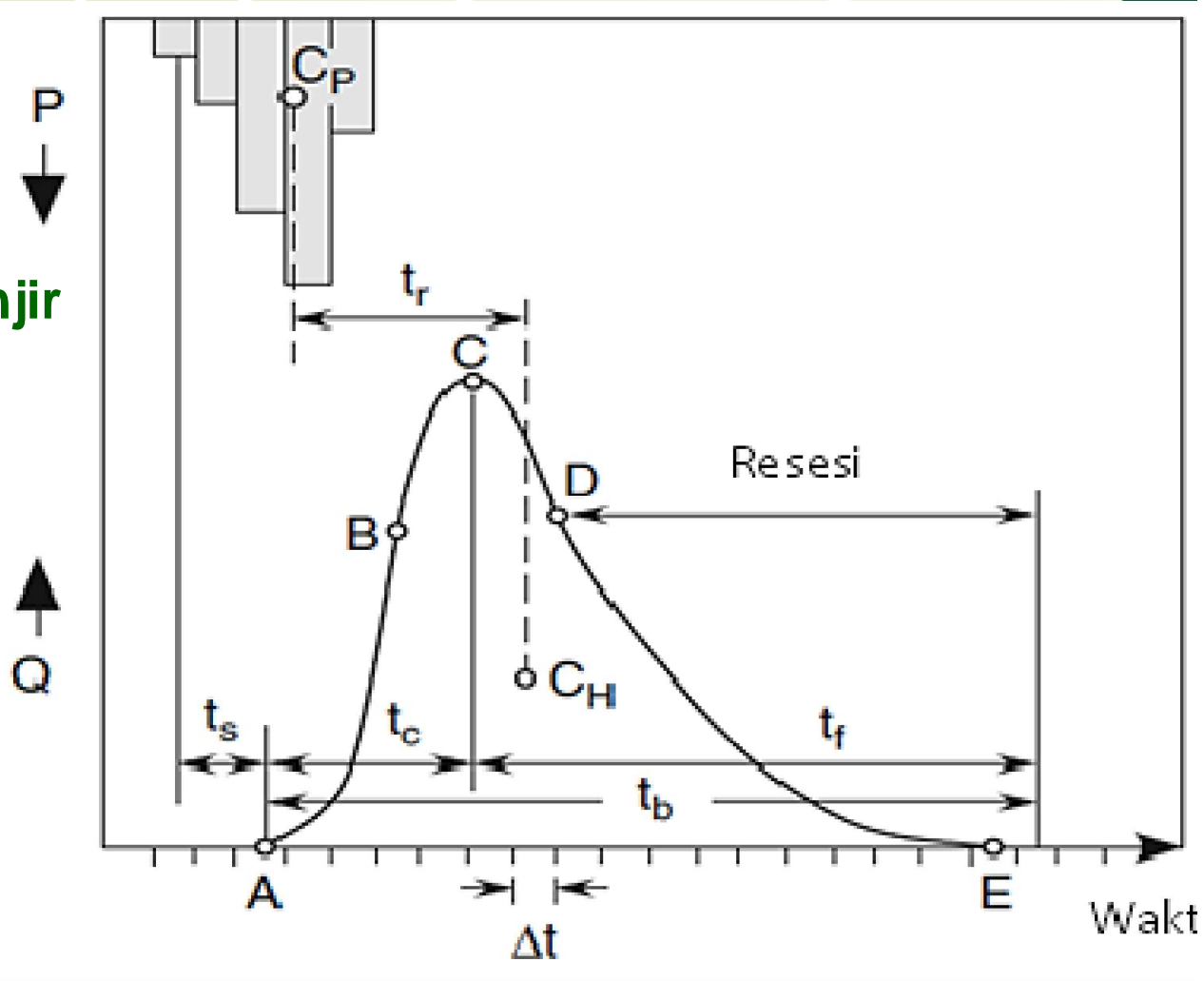

Gambar 1. Hidrograf Mataair (Kresic and Bonacci, 2010) 


\section{Alur Perhitungan Derajat Karstifikasi Metode Rashed (2012)}

\section{Pemilihan Hidrograf Banjir}

\section{Memilih hidrograf banjir yang memiliki periode resesi cukup panjang}

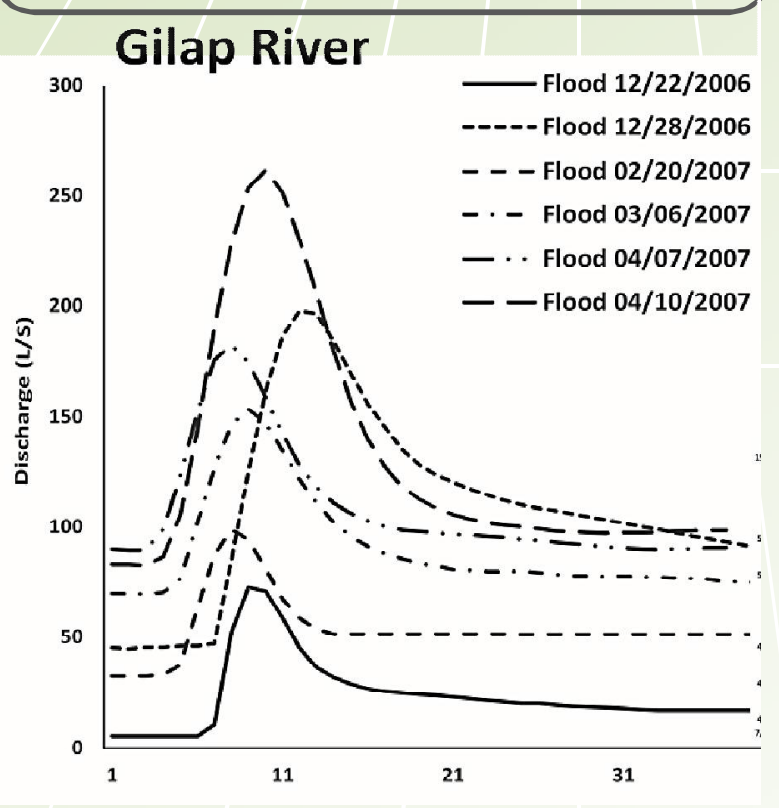

Menggunakan metode : Straight Line Methods, atau Recursive Digital Filtering (Eckhardt)

\section{Pemisahan \\ Aliran \\ Dasar}

\section{Perhitungan \\ Derajat \\ Karstifikasi}

Hasil dari perhitungan

rumus kemudian

diklasifikasikan (Tabel 1)

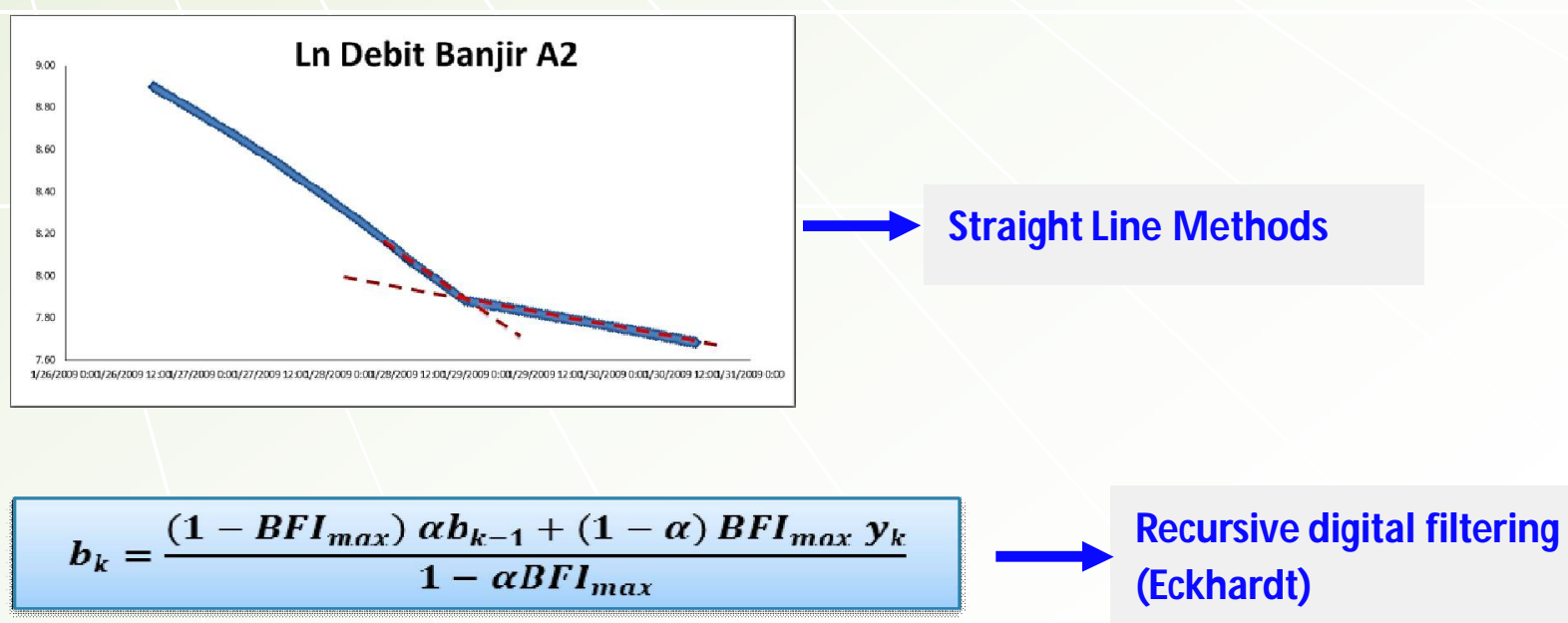




\section{Rumus}

\section{Rumus Perhitungan Derajat Karstifikasi $\left(D_{k}\right)$ menurut Metode Rashed (2012)}

$$
D_{k}=\frac{Q_{\max }}{Q_{\min }} \frac{t_{\text {event }}}{t_{\text {peak }}}
$$

Sedangkan $t_{\text {event }}$ dan $t_{\text {peak }}$ didapat dari

$$
t_{\text {event }}=t_{C}-t_{A}
$$

$$
t_{\text {peak }}=t_{B}-t_{\Lambda}
$$

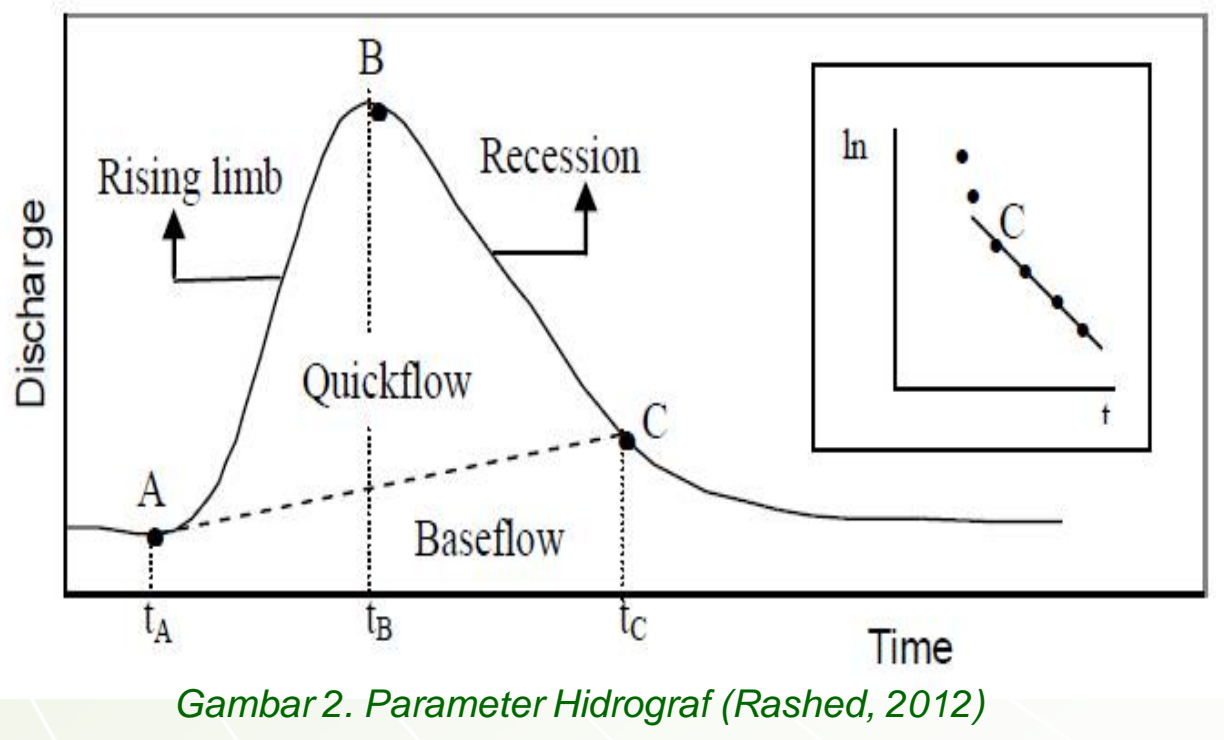

$$
\begin{aligned}
& Q_{\max }=\text { Debit maksimum } / \text { debit puncak ( } \mathrm{m}^{3} / \text { detik) }=\mathrm{B} \\
& Q_{\min }=\text { Debit minimum saat kurva mulai naik }\left(\mathrm{m}^{3} / \text { detik }\right)=A \\
& t_{\mathrm{A}} \quad=\text { Waktu ketika mulai menaiknya hidrograf (jam) } \\
& t_{B} \quad=\text { Waktu ketika debit maksimum terekam (jam) } \\
& t_{c} \quad=\text { Waktu ketika hidrograf sudah mencapai normal kembali (jam) }
\end{aligned}
$$


1 Banjir 7 (9 Maret 2014, 4:30 AM)

2 Tanggal, Waktu

3 03/08/14 08:45:00 PM

4 03/08/14 09:00:00 PM

5 03/08/14 09:15:00 PM

6 03/08/14 09:30:00 PM

7 03/08/14 09:45:00 PM

8 03/08/14 10:00:00 PM

9 03/08/14 10:15:00 PM

10 03/08/14 10:30:00 PM

11 03/08/14 10:45:00 PM

12 03/08/14 11:00:00 PM

13 03/08/14 11:15:00 PM

14 03/08/14 11:30:00 PM

15 03/08/14 11:45:00 PM

16 03/09/14 12:00:00 AM

17 03/09/14 12:15:00 AM

18 03/09/14 12:30:00 AM

19 03/09/14 12:45:00 AM

20 03/09/14 01:00:00 AM

21 03/09/14 01:15:00 AM

22 03/09/14 01:30:00 AM

23 03/09/14 01:45:00 AM

24 03/09/14 02:00:00 AM

25 03/09/14 02:15:00 AM

26 03/09/14 02:30:00 AM

27 03/09/14 02:45:00 AM

28 03/09/14 03:00:00 AM

29 03/09/14 03:15:00 AM

30 03/09/14 03:30:00 AM

31 03/09/14 03:45:00 AM

32 03/09/14 04:00:00 AM

33 03/09/14 04:15:00 AM

34 03/09/14 04:30:00 AM

35 03/09/14 04:45:00 AM

36 03/09/14 05:00:00 AM
TMA (Meter) Debit (m³ $/ \mathrm{dt})$

$\begin{array}{ll}0.837 & 2.533196 \\ 0.923 & 3.040492 \\ 0.968 & 3.305938 \\ 0.946 & 3.176165 \\ 0.914 & 2.987403\end{array}$

2.987403

$0.87 \quad 2.727856$

$0.832 \quad 2.503702$

$0.807 \quad 2.356232$

$0.792 \quad 2.267750$

$0.826 \quad 2.468309$

$0.932 \quad 3.093582$

$1.03 \quad 3.671664$

$1.093 \quad 4.043288$

$1.133 \quad 4.279240$

$1.147 \quad 4.361824$

$1.148 \quad 4.367722$

$1.129 \quad 4.255645$

$1.119 \quad 4.196657$

$1.099 \quad 4.078681$

$1.081 \quad 3.972503$

$1.086 \quad 4.001997$

$1.094 \quad 4.049187$

$1.109 \quad 4.137669$

$1.136 \quad 4.296937$

$1.168 \quad 4.485698$

$1.207 \quad 4.715752$

$1.236 \quad 4.886817$

$1.268 \quad 5.075578$

$1.304 \quad 5.287935$

$1.331 \quad 5.447203$

$1.351 \quad 5.565179$

$1.357 \quad 5.600572$

$1.352 \quad 5.571078$

$1.349 \quad 5.553381$
Time to Peak $\left(t_{\text {peak }}\right)$

$=7,75 \mathrm{Jam}$

\section{Debit Puncak $\left(Q_{\max }\right)$}

\section{Langkah Kerja-1}

Hidrograf banjir yang digunakan sebagai contoh adalah kejadian banjir tanggal 9 Maret 2014 pukul 04.30 WIB dengan debit puncak 5,6006 m³/detik. 


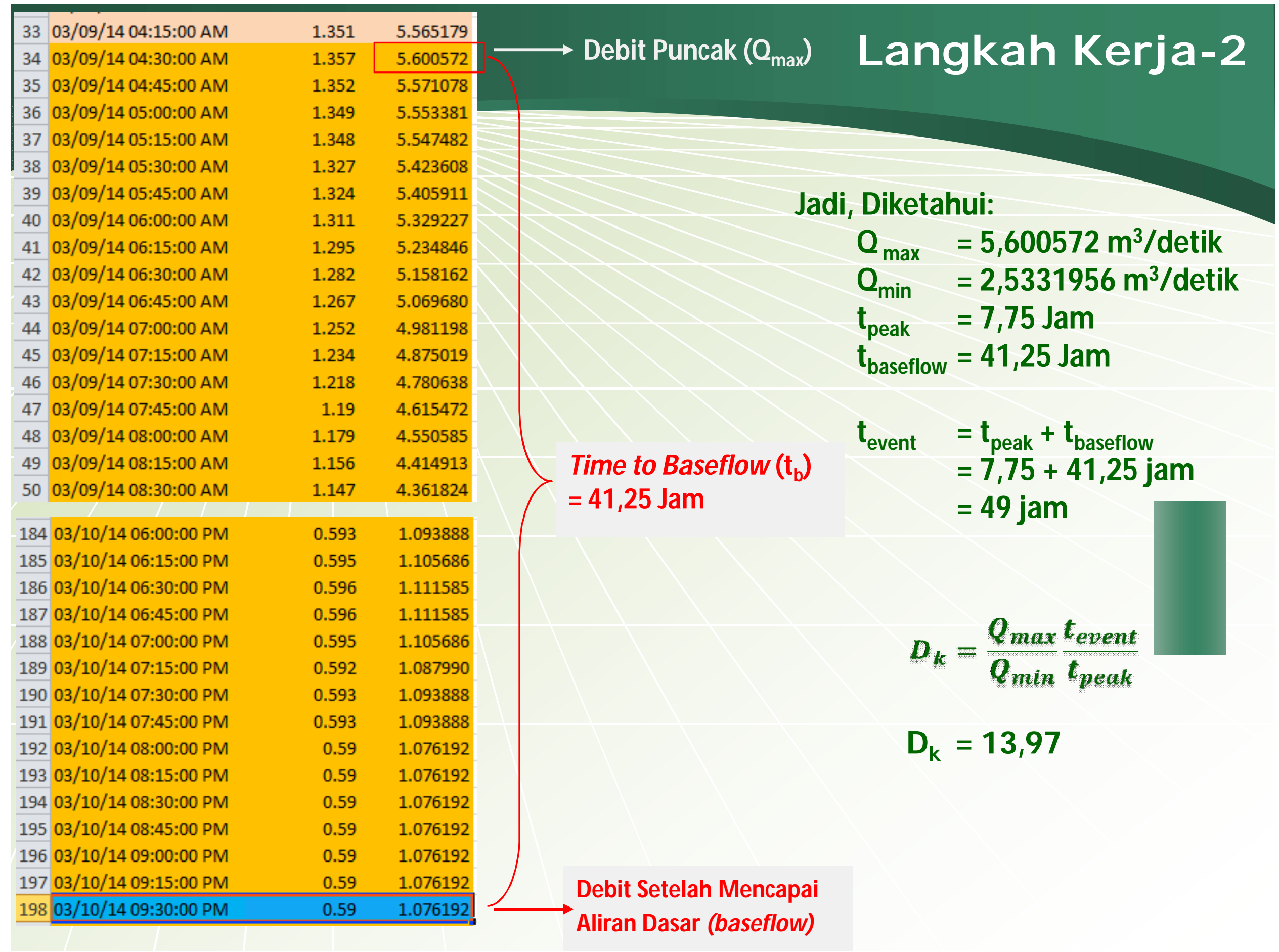




\section{Klasifikasi Derajat Karstiffkasi Rashed (2012)}

Tabel 1. Klasifikasi Derajat Karstifikasi Akuifer Karst $\left(D_{k}\right)$

$D_{k}$

Klasifikasi Akuifer

$<10$ Akuifer yang sistemnya didominasi aliran diffuse (Darcian aquifer)

10 - 20 Akuifer yang telah terkarstifikasi sebagian (Partially karstified aquifer)

$20-60$ Akuifer yang telah terkarstifikasi (Karstified aquifer)

>60 Akuifer yang telah terkarstifikasi secara lanjut (Highly karstified aquifer) 


\section{Metode Perhitungan Derajat Karstifikasi}

\section{METODE MALI K AND VOTJ KOVA (2012)}

\section{Berdasarkan Analisis Kurva Resesi}
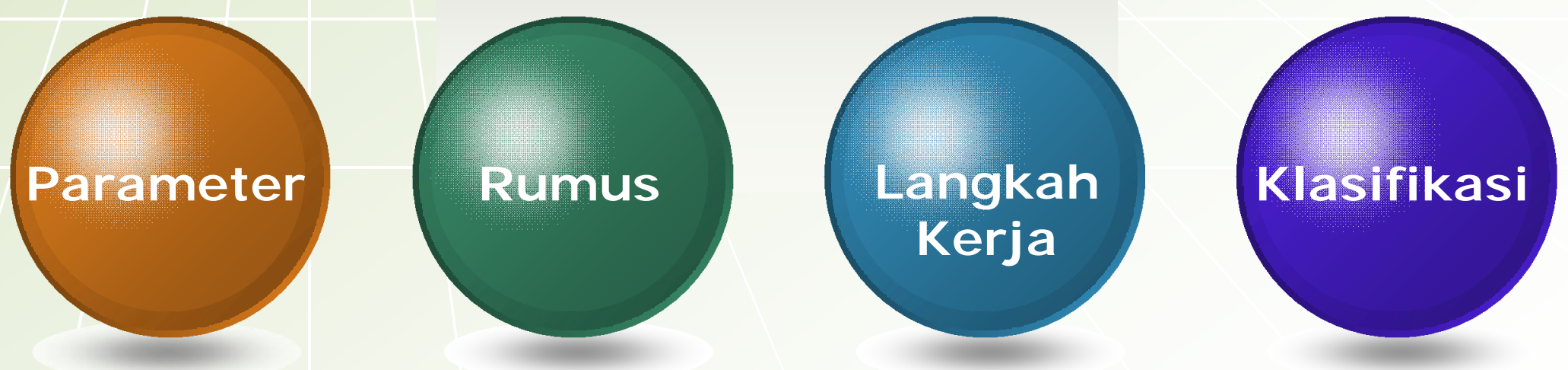


\section{Metode Perhitungan Malik and Votjkova (2012)}

\section{Pendekatan}

\section{Dasar Perhitungan}

\section{Pendekatan Analisis Kurva Resesi}

Kurva Resesi adalah bagian dari hidrograf yang menurun (the falling limb), dimulai dari debit puncak hingga debit mencapai aliran dasar.
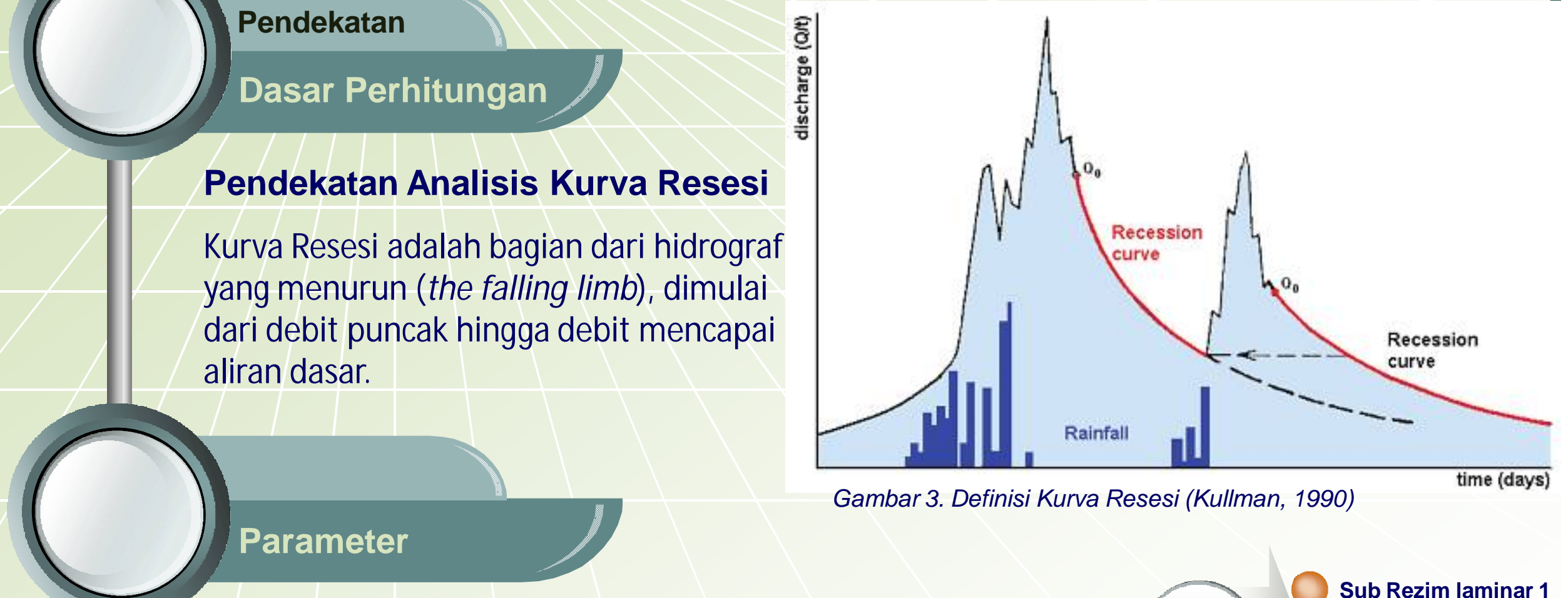

Kurva resesi memiliki beberapa sub rezim aliran, yang dinyatakan sebagai aliran laminar dan aliran turbulen.

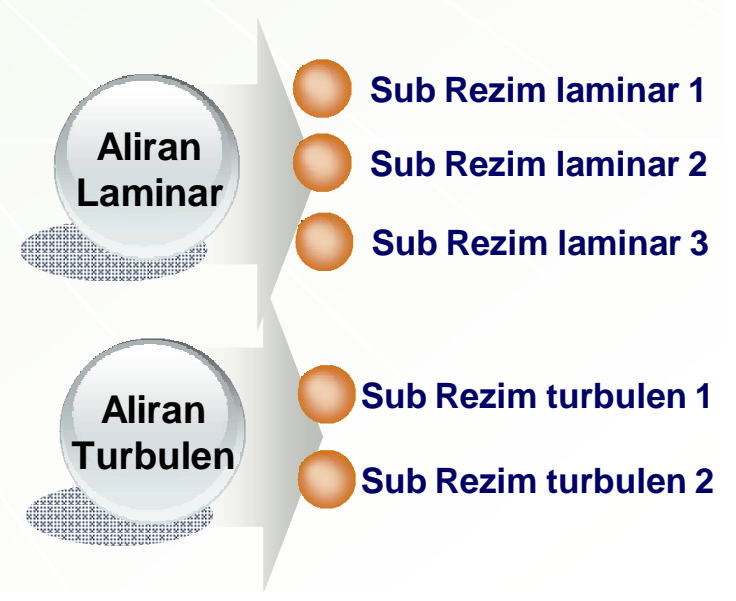

Perbedaan utama metode ini dengan metode-metode sebelumnya adalah satu kurva resesi bisa memiliki satu atau lebih sub rezim aliran. 


\section{Rumus}

Nilai koefisien aliran laminar $(\alpha)$ berprinsip pada Rumus M aillet, 1905 yang diformulasikan pada Rumus 1.

Aliran

Laminar
Ket :

$\mathrm{Q}_{\mathrm{t}}=$ Debit dalam satuan waktu selama masa resesi $\left(\mathrm{m}^{3} / \mathrm{dt}\right)$

(1) $Q_{0}=$ Debit pada awal resesi $\left(\mathrm{m}^{3} / \mathrm{dt}\right)$

$\alpha=$ Koefisien resesi

$\mathrm{t} \quad=$ Waktu yang dilalui antara $\mathrm{Q}_{\mathrm{t}}$ dan $\mathrm{Q}_{0}$

Nilai koefisien aliran turbulen ( $\beta$ ) dihitung dari Rumus Kullman, 1983 dalam Malik dan Votjkova (2012) yang diformulasikan pada Rumus 2.

Aliran Turbulen

Koefisien $\beta$ pada Rumus 2 dihitung dari Rumus Drogue, 1972 dalam Fiorillo (2014), dan diformulasikan pada Rumus 3.

$$
\beta=\alpha\left(Q_{0}{ }^{-1 / n}\right)
$$

Ket :

$B=$ Koefisien aliran turbulen

$\alpha=$ Koefisien aliran laminar

$\mathrm{Q}_{0}=$ Debit sebelumnya $\left(\mathrm{m}^{3} / \mathrm{dt}\right)$

$n=\frac{3}{2} \approx 1.5$ 


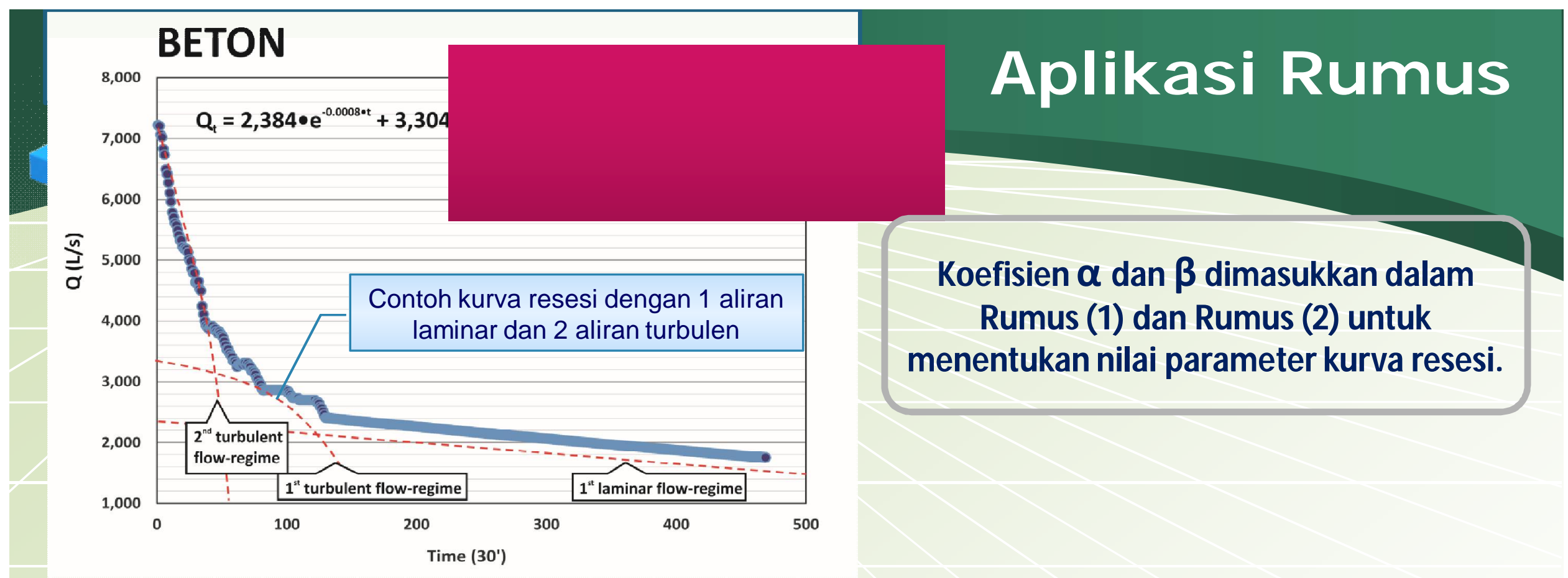

\section{PETOYAN}

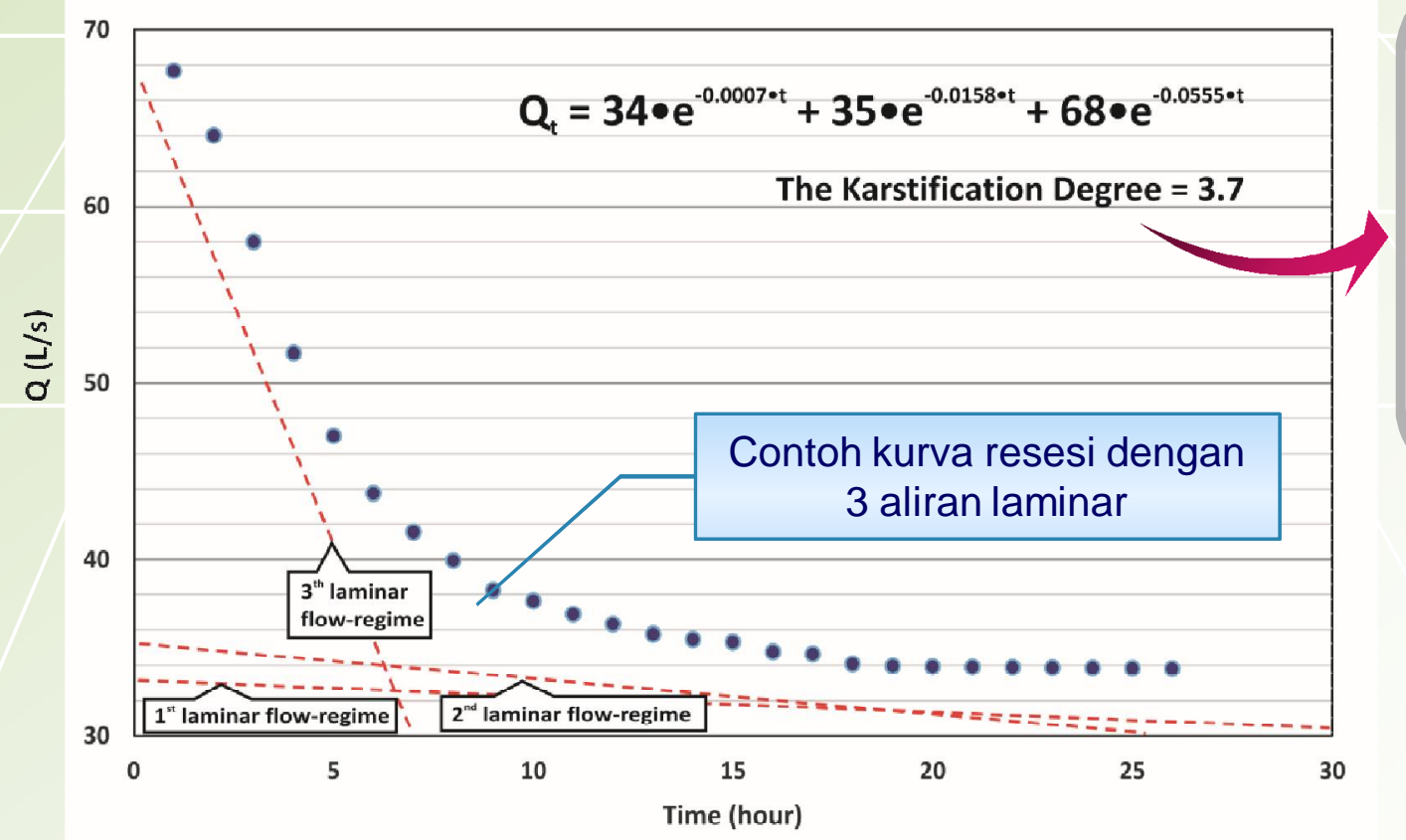

Tingkat Karstifikasi ditentukan berdasarkan nilai linear dan koefisien resesi sub regim aliran

Tingkat Karstifikasi memiliki nilai antara 0-10 


\section{Langkah Kerja-1}

\section{Perhitungan Koefisien Aliran Laminar ( $\alpha)$}

Kurva resesi yang digunakan sebagai contoh adalah kejadian banjir tanggal 9 Maret 2014 pukul 04.30 WIB dengan debit puncak 5,6006 m³/detik.

\begin{tabular}{|c|c|c|c|c|c|}
\hline 4 & A & B & C & D & $E$ \\
\hline 1 & Tanggal, Waktu & TMA (Meter) & Debit $\left(\mathrm{m}^{3} / \mathrm{dt}\right)$ & $\alpha$ Laminar & \\
\hline 2 & 03/09/14 04:30:00 AM & 1.357 & 5.6006 & & \\
\hline 3 & 03/09/14 05:30:00 AM & 1.327 & 5.4236 & 0.032107 & \\
\hline 4 & 03/09/14 06:30:00 AM & 1.282 & 5.1582 & 0.050181 & \\
\hline 5 & 03/09/14 07:30:00 AM & 1.218 & 4.7806 & 0.076006 & \\
\hline 6 & 03/09/14 08:30:00 AM & 1.147 & 4.3618 & 0.091684 & \\
\hline 7 & 03/09/14 09:30:00 AM & 1.08 & 3.9666 & 0.094980 & \\
\hline 8 & 03/09/14 10:30:00 AM & 1.021 & 3.6186 & 0.091830 & \\
\hline 9 & 03/09/14 11:30:00 AM & 0.977 & 3.3590 & 0.074429 & \\
\hline 10 & 03/09/14 12:30:00 PM & 0.96 & 3.2587 & 0.030308 & \\
\hline 11 & 03/09/14 01:30:00 PM & 0.943 & 3.1585 & 0.031256 & \\
\hline 12 & 03/09/14 02:30:00 PM & 0.912 & 2.9756 & 0.059640 & \\
\hline 13 & 03/09/14 03:30:00 PM & 0.825 & 2.4624 & 0.189307 & \\
\hline 14 & 03/09/14 04:30:00 PM & 0.755 & 2.0495 & 0.183548 & \\
\hline 15 & 03/09/14 05:30:00 PM & 0.711 & 1.7899 & 0.135407 & \\
\hline 16 & 03/09/14 06:30:00 PM & 0.682 & 1.6189 & 0.100450 & \\
\hline 17 & 03/09/14 07:30:00 PM & 0.67 & 1.5481 & 0.044710 & \\
\hline 18 & 03/09/14 08:30:00 PM & 0.665 & 1.5186 & 0.019236 & \\
\hline 19 & 03/09/14 09:30:00 PM & 0.662 & 1.5009 & 0.011722 & \\
\hline 20 & 03/09/14 10:30:00 PM & 0.659 & 1.4832 & 0.011861 & \\
\hline 21 & 03/09/14 11:30:00 PM & 0.656 & 1.4655 & 0.012003 & \\
\hline
\end{tabular}

$$
\begin{gathered}
\alpha=\frac{\left(\operatorname{Ln} Q_{0}-\operatorname{Ln} Q_{t}\right)}{T_{t}-T_{0}} \\
\alpha=(\operatorname{Ln}(\mathrm{C} 2)-\operatorname{Ln}(\mathrm{C} 3)) / 1
\end{gathered}
$$




\section{Langkah Kerja-2}

\section{Koefisien aliran turbulen $(\beta)$ dihitung menggunakan Rumus 3}

A

1 Tanggal, Waktu

2 03/09/14 04:30:00 AM

3 03/09/14 05:30:00 AM

4 03/09/14 06:30:00 AM

5 03/09/14 07:30:00 AM

6 03/09/14 08:30:00 AM

7 03/09/14 09:30:00 AM

8 03/09/14 10:30:00 AM

9 03/09/14 11:30:00 AM

10 03/09/14 12:30:00 PM

11 03/09/14 01:30:00 PM

12 03/09/14 02:30:00 PM

13 03/09/14 03:30:00 PM

14 03/09/14 04:30:00 PM

15 03/09/14 05:30:00 PM

16 03/09/14 06:30:00 PM

17 03/09/14 07:30:00 PM

18 03/09/14 08:30:00 PM

19 03/09/14 09:30:00 PM

20 03/09/14 10:30:00 PM

21 03/09/14 11:30:00 PM

22 03/10/14 12:30:00 AM

23 03/10/14 01:30:00 AM
B

\begin{tabular}{|r|r|r|}
\hline TMA (Meter) & Debit $\left(\mathrm{m}^{3} / \mathrm{dt}\right)$ & $\alpha$ Laminar \\
\hline 1.357 & 5.6006 & \\
\hline 1.327 & 5.4236 & 0.03210 \\
\hline 1.282 & 5.1582 & 0.05018 \\
\hline 1.218 & 4.7806 & 0.07600 \\
\hline 1.147 & 4.3618 & 0.09168 \\
\hline 1.08 & 3.9666 & 0.09498 \\
\hline 1.021 & 3.6186 & 0.09183 \\
\hline 0.977 & 3.3590 & 0.07442 \\
\hline 0.96 & 3.2587 & 0.03030 \\
\hline 0.943 & 3.1585 & 0.03125 \\
\hline 0.912 & 2.9756 & 0.05964 \\
\hline 0.825 & 2.4624 & 0.18930 \\
\hline 0.755 & 2.0495 & 0.18354 \\
\hline 0.711 & 1.7899 & 0.13540 \\
\hline 0.682 & 1.6189 & 0.10045 \\
\hline 0.67 & 1.5481 & 0.04471 \\
\hline 0.665 & 1.5186 & 0.01923 \\
\hline 0.662 & 1.5009 & 0.01172 \\
\hline 0.659 & 1.4832 & 0.01186 \\
\hline 0.656 & 1.4655 & 0.01200 \\
\hline 0.653 & 1.4478 & 0.012149 \\
\hline 0.647 & 1.4124 & 0.024749 \\
\hline & & \\
\hline & & \\
\hline 056 & &
\end{tabular}

\begin{tabular}{l|l} 
E & $F$
\end{tabular}

$\beta$ Turbulen

0.010181

0.016256

0.025459

0.032307

0.035578

0.036647

0.031578

0.013513

0.014220

0.027704

0.091506

0.100656

0.083922

0.068138

0.032428

0.014374

0.008872

0.009048

0.009229

0.009416

0.019338

$$
\begin{aligned}
& \beta=\alpha\left(Q_{0}{ }^{-1 / n}\right) \\
& \beta=D 3 *\left(C 2^{\wedge}(-0.66667)\right)
\end{aligned}
$$




\section{Langkah Kerja-3}

\section{Penentuan Nilai koefisien aliran laminar $(\alpha)$ dan turbulen $(\beta)$}

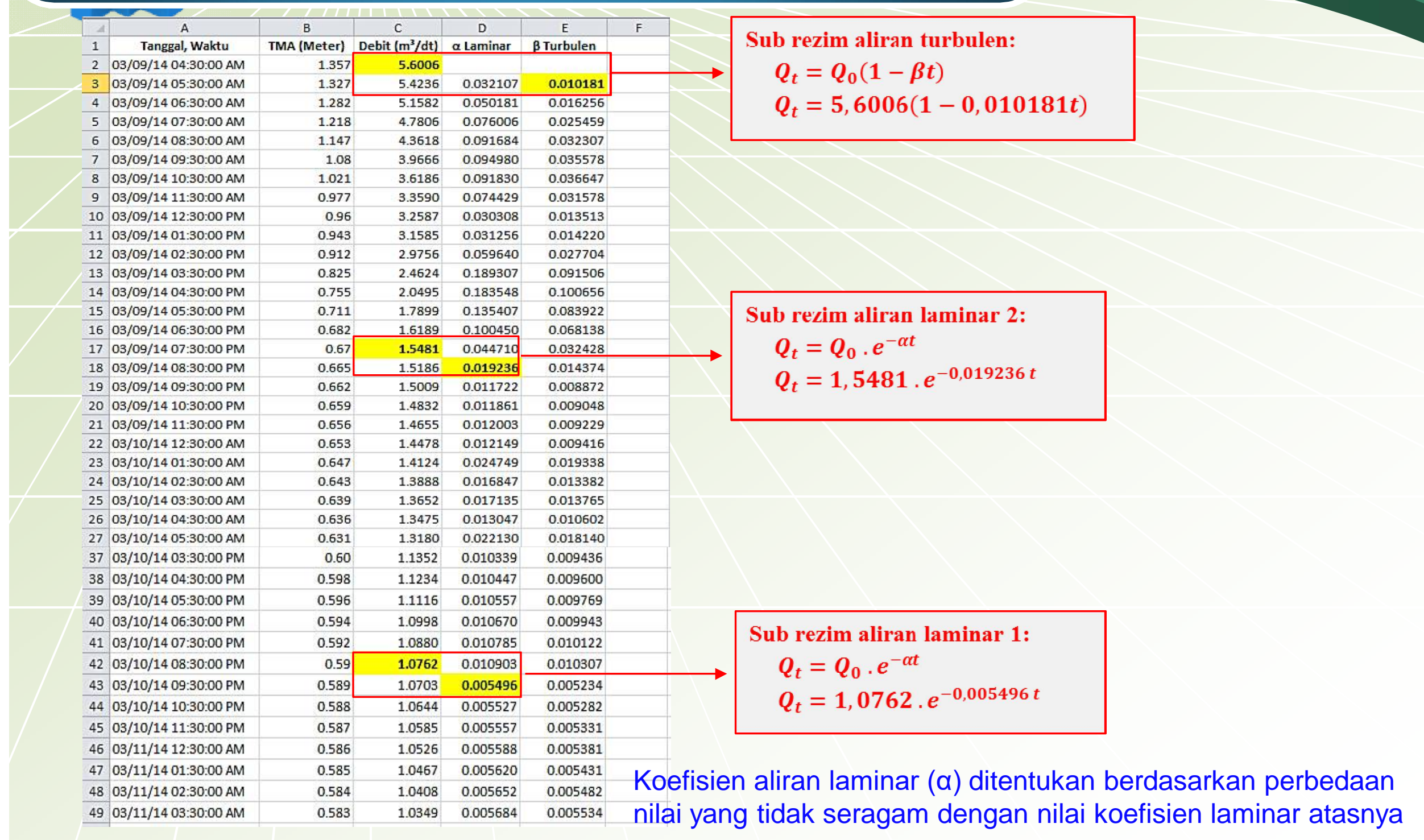




\section{Langkah Kerja-4}

4. Hasil penentuan sub rezim aliran ditampilkan dalam graftk

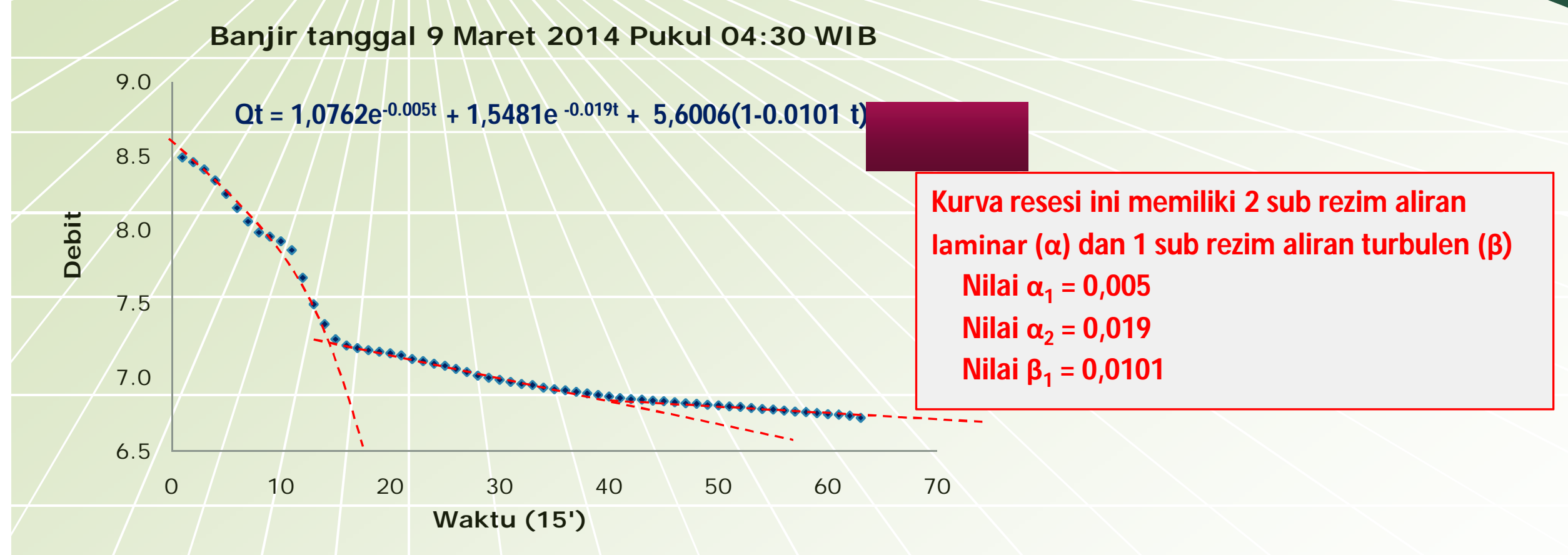

5. Menentukan Tingkat Karstiffkasi ( Nilai 0-10)

Tingkat karstifikasi dilihat dari jumlah sub rezim aliran laminar dan sub rezim aliran turbulen, serta nilai $\alpha$ dan nilai $\beta$ (Kriteria dapat dilihat pada Tabel 2). 


\section{Referensi}

Adji, T.N., M ujib, M .A., Fatchurrohman, H., Bahtiar, I.Y., (2014). Analisis tingkat perkembangan akuifer karst di Kawasan Karst Gunung Sewu, DIY dan Karst Rengel, Tuban, Jawa Timur, dipresentasikan pada Seminar Nasional Pekan IImiah Tahunan Ikatan Geograf Indonesia (PIT IGI) ke XVII di Universitas Negeri Yogyakarta, 15-17 November 2014.

Eckhardt, K., (2005). How to construct recursive digital filters for baseflow separation. Hydrological Processess. 19: $507-515$

Fiorillo, F., (2014). The recession of spring hydrographs, focused on karst aquifer. Water resour manage 28: 1781-1805

Kresic, N. and Bonacci, O. 2010. Spring Discharge Hydrograph. In Kresic, N. and Zoran Stevanovic. 2010. Groundwater Hydrology of Springs: engineering, theory, management, and sustainability. Oxford: Butterworth-Heinemann.

Malik, P., (2007). Assessment of regional kastification degree and groundwater sensitivity to pollution using hydrograph analysis in the Velka Fatra M ountains, Slovakia. Environ Geol 51: 707-711.

Malik, P. and Vojtkova, S., (2010). Use of combined recession curve analysis of neighbouring karstic springs to reveal karstification degree of groundwater springing routes. In Andreo, B. et al (Eds) Advances in Research in Karst Media. Berlin: Springer

Malik, P. and Vojtkova, S., (2012). Use of recession-curve analysis for estimation of karstification degree and its application in assessing overflow/underflow conditions in closely spaced karstic springs. Environmental Earth Sciences, 65: 2245-2257.

M ujib, M.A., (2015). Analisis karakteristik dan tingkat karstifikasi akuifer karst di sistem Mataair Ngerong, Karst Rengel, Tuban, Jawa Timur. Tesis tidak dipublikasikan, Fakultas Geografi, Universitas Gadjah Mada

Rashed, K.A., (2012). Assessing degree of karstification: a new method of classifying karst aquifers. Sixteenth International Water Technology Conference, IWTC 16, Istanbul, Turkey 